\title{
Biological effects of tris (1-chloro-2-propyl) phosphate (TCPP) on immunity in mussel Mytilus galloprovincialis
}

\author{
Huifeng $\mathrm{Wu}^{\mathrm{a}, \mathrm{b}}$, Mingyu Zhong ${ }^{\mathrm{a}, \mathrm{c}}$, Zhen $\mathrm{Lu}^{\mathrm{a}, \mathrm{c}}$, Xiujuan Shan ${ }^{\mathrm{b}}$, Fei $\mathrm{Li}^{\mathrm{a}}$, Chenglong $\mathrm{Ji}^{\mathrm{a}, \mathrm{b}}$, Ming Cong ${ }^{\mathrm{a}, *}$ \\ ${ }^{a}$ Key Laboratory of Coastal Zone Environmental Processes and Ecological Remediation, Yantai Institute of Coastal Zone Research (YIC), Chinese Academy of Sciences \\ (CAS), Shandong Provincial Key Laboratory of Coastal Zone Environmental Processes, YICCAS, Yantai, 264003, PR China \\ ${ }^{\mathrm{b}}$ Laboratory for Marine Fisheries Science and Food Production Processes, Qingdao National Laboratory for Marine Science and Technology, Qingdao, 266237, PR China \\ ${ }^{\mathrm{c}}$ University of Chinese Academy of Sciences, Beijing, 100049, PR China
}

\section{A R T I C L E I N F O}

\section{Keywords:}

Organophosphate flame retardants (OPFRs)

Tris (2-chloropropyl) phosphate (TCPP)

Biological effects

ImmunityMytilus galloprovincialis

\begin{abstract}
A B S T R A C T
Organophosphate flame retardants (OPFRs) are increasingly produced and used as alternatives of brominated flame-retardants (BFRs) and have become emerging marine environmental contaminants. So far, however, little is known regarding the biological effects of OPFRs in marine organisms. In this study, the biological effects of one of the most abundant OPFRs, tris (1-chloro-2-propyl) phosphate (TCPP), on the immunity in mussel Mytilus galloprovincialis were characterized by testing the reactive oxygen species, apoptosis, antioxidant system and immunity related gene expressions. Results indicated that both TCPP exposures (10 and $\left.100 \mathrm{nmol} \mathrm{L}^{-1}\right) \mathrm{sig}_{\text {- }}$ nificantly $(p<0.01)$ enhanced reactive oxygen species production and the high dose of TCPP induced more apoptosis and oxidative stress in mussel hemocytes. TCPP also induced an obvious hormesis phenomenon (low dose inhibition and high dose stimulation) in mussel hemocytes, as indicated by the gene expression profiles of caspase 8 and mytimacin. The down-regulated gene expression levels of lysozymes suggested that both TCPP exposures inhibited the innate immunity in mussel $M$. galloprovincialis. The significantly $(p<0.01)$ increased gene expression levels of TLR, galectin, PGRP and LITAF demonstrated that TCPP induced dose-dependent immune stress in mussels. Overall, this work suggested that TCPP could influence the immune system in marine mussel M. galloprovincialis.
\end{abstract}

\section{Introduction}

Organophosphate flame retardants (OPFRs) are increasingly produced and used as alternatives of brominated flame-retardants (BFRs), such as the polybrominated diphenyl ethers (PBDEs) (Wang et al., 2015). Nowadays, the OPFRs can be frequently detected in seawaters and sediments from the Bohai Sea (Zhong et al., 2018; Zhong et al., 2017), which has posed a risk on marine organisms and subsequent human health via food chains. Among the OPFRs, the tris (1-chloro-2propyl) phosphate (TCPP) is one of the most frequently detected halogenated OPFRs in both waters and sediments due to its wide usage as flame retardants in polyurethane foam and epoxy resin, with a concentration up to $31.4 \mathrm{ng} \mathrm{L}^{-1}$ in the seawater from the Bohai Sea in China (Zhong et al., 2018; Zhong et al., 2017; Andresen et al., 2004; Bacaloni et al., 2008; Martinez-Carballo et al., 2007; Regnery and Puttmann, 2010). Although the adverse effects to human health and ecosystem of OPFRs have been reported in a few researches (Reemtsma et al., 2008; Ren et al., 2008; Pillai et al., 2014), there is a lack of studies on the biological effects of OPFRs in marine organisms.
Compared with brominated flame retardants, such as PBDEs and tetrabromobisphenol A (TBBPA), however, OPFRs have received little attention with regard to the adverse biological effects and ecological risk. Therefore, it is necessary to characterize the biological effects of OPFRs in marine organisms.

The marine bivalve, mussel Mytilus galloprovincialis, distributes widely in the Bohai Sea and is consumed as popular seafood by local residents. Therefore mussel $M$. galloprovincialis has been an important species in marine aquaculture industry in China. In addition, as a filterfeeder, mussel M. galloprovincialis plays an important role in coastal ecosystem. Due to its high capacity to accumulate environmental contaminants, this bivalve is also a preferable bioindicator used in marine biology and ecotoxicology, as well as in 'Mussel Watch Program' (Goldberg et al., 1983; Jernelov, 1996). However, there was a lack of investigations on the toxicological effects of OPFRs in marine mussels.

As an emerging class of marine environmental contaminants in the Bohai Sea, the OPFRs have been of great concern to researchers. In this work, the mussel M. galloprovincialis was used as experimental animal to study the chronic biological effects of one of the most frequently

\footnotetext{
* Corresponding author.

E-mail address: mcong@yic.ac.cn (M. Cong).
} 
detected OPFRs, TCCP. The immune system of M. galloprovincialis is innate and consists of an open and vascular system including hemocytes and humoral components (Tanguy et al., 2018). The hemocytes provide the first line of defense against immune stressors by phagocytosis and encapsulation. Then, the humoral components including lysosomal enzymes, aminopeptidases, lectins and antimicrobial molecules may be produced to destroy immune stressors (Tanguy et al., 2018). In this study, therefore, the reactive oxygen species, apoptosis, antioxidant system and immunity-related gene expressions in hemocytes were tested to elucidate the biological effects of TCCP on the immunity in mussel M. galloprovincialis.

\section{Materials and methods}

\subsection{Animal culture and experiment design}

Adult mussels Mytilus galloprovincialis (shell length: 4-6 cm) were purchased from a local culturing farm (Yantai, China). After transported to laboratory, the mussels were acclimatized in filtered and aerated seawater in glass containers for 7 days and then were randomly divided into four groups (seawater control, solvent control, low and high doses of TCPP treatments). For each group, there were two replicate containers each containing 20 individual mussels. The mussels cultured in the filtered seawater and filtered seawater containing $0.00025 \%$ DMSO $(\mathrm{v} / \mathrm{v})$ were used as seawater control and solvent control groups, respectively. TCPP (CAS No. 13,674-84-5) was purchased from J\&K Chemical Co., Ltd. The TCPP-treated mussels were exposed to two concentrations ( 10 and $100 \mathrm{nmol} \mathrm{L}^{-1}$ ) of TCPP, respectively. The concentrations of TCPP stock solutions were 1 and $10 \mathrm{mg} \mathrm{L}^{-1}$ in DMSO to ensure the same DMSO concentrations in the TCPP-exposed groups to that of solvent control group. During the periods of acclimation and exposure, the mortalities for all groups were recorded and found to be less than $5 \%$ without significant differences among the groups. All the animals were kept at $18-20^{\circ} \mathrm{C}$ under a photoperiod of $12 \mathrm{~h}$ light and $12 \mathrm{~h}$ dark, and fed with $1.5 \mathrm{~g}$ Chlorella vulgaris per day. After a chronic exposure for 42 days, the mussels were taken out of the exposure tanks and opened by using scalpels to cut off the adductor muscle carefully. Then, the hemolymph was collected from the adductor by using sterile injection syringes and mixed immediately with equivoluminal anticoagulant $(20.80 \mathrm{~g}$ of glucose, $8.00 \mathrm{~g}$ of sodium citrate, $3.36 \mathrm{~g}$ of ethylene diamine tetraacetic acid (EDTA), and $22.50 \mathrm{~g}$ of sodium chloride in $1 \mathrm{~L}$ of pure water). Then the hemolymph samples were filtrated by screen spun silks of 300 meshes to exclude impurities and used in subsequent experiments. For all the experiments, 4 biological replicates were used in each group and each biological replicate consisted of blood from four individual mussels.

\subsection{Hemocytes RNA extraction, cDNA synthesis and gene expression analysis}

Approximately, $10 \mathrm{~mL}$ of mussel blood was centrifuged $(5000 \mathrm{rpm}$ for $5 \mathrm{~min}$ ) to enrich hemocytes and TRIzol Reagent (Invitrogen) was used in total RNA extraction. The extracted RNA was purified with RNeasy mini kit (Qiagen) and resuspended in purified water (RNase free). Total RNA quality and concentrations were evaluated by the A260/280 and A260/230 spectrophotometric ratios using the NanoDrop 1000 spectrophotometer (Thermo Scientific). By employing M-MLV reverse transcriptase (Promega) and Oligo dT primers, $500 \mathrm{ng}$ of total RNA was used to synthesize cDNA. All the processes were followed the manufacturers' instructions.

For gene expression analysis, 12 immunity related genes were selected and the corresponding primers were referred to the publications (Wang et al., 2013, 2012; Martins et al., 2014; Gerdol et al., 2012; You, 2013) and listed in Table 1. The 7300 Real Time PCR System (Applied Biosystems) was employed to conduct qPCR analysis. Briefly, $6 \mu \mathrm{L}$ of 50 times diluted cDNA, $10 \mu \mathrm{L}$ of SYBR green PCR master mix (Applied
Biosystems), $0.8 \mu \mathrm{L}(10 \mathrm{mM})$ of forward and reverse primer and $3.2 \mu \mathrm{L}$ of nuclease-free water (Qiagen) were added to $20 \mu \mathrm{L}$ of reaction volume. The qPCR program was designed as $95^{\circ} \mathrm{C}$ for $7 \mathrm{~min}$, followed by 40 cycles of $95^{\circ} \mathrm{C}$ for $15 \mathrm{~s}$ and $60^{\circ} \mathrm{C}$ for $30 \mathrm{~s}$ and $60^{\circ} \mathrm{C}$ for $10 \mathrm{~min}$. The M. galloprovincialis $18 \mathrm{~S}$ rRNA gene was chosen as reference gene and the comparative CT method $\left(2^{-\Delta \Delta \mathrm{Ct}}\right.$ method) was used to analyze the expression level of the genes (Livak and Schmittgen, 2001).

\subsection{Analysis of reactive oxygen species (ROS) and apoptosis}

Approximately, $600 \mu \mathrm{L}$ of mussel blood was centrifuged (5000 rpm for $5 \mathrm{~min}$ ) to enrich hemocytes. Following the manufacturer's instructions, the ROS Assay Kit (the method of 2', 7'-dichlorofluorescin (DCF) labeling, Beyotime) and the One Step TUNEL Apoptosis Assay Kit (the method of fluorescein isothiocyanate (FITC) labeling, Beyotime) were used in pretreatment of the ROS and apoptosis analysis, respectively. Then the treated hemocytes (10,000 individuals for one sample) were screened and sorted by the flow cytometer (FACSAria) at excitation wavelength of $488 \mathrm{~nm}$ and emission wavelength of $525 \mathrm{~nm}$.

\subsection{Analysis of superoxide dismutase (SOD) activity and malondialdehyde (MDA) content}

About $600 \mu \mathrm{L}$ mussel blood was centrifuged ( $5000 \mathrm{rpm}$ for $5 \mathrm{~min}$ ) to enrich hemocytes. Following the manufacturer's instructions, SOD Assay Kit (Nanjing Jiancheng Bioengineering Institute) and MDA Assay Kit (Nanjing Jiancheng Bioengineering Institute) were used in pretreatment of the SOD and MDA analysis, respectively. Then the treated samples were analyzed by using Infinite M200 microplate spectrophotometer (Tecan Infinite).

\subsection{Statistical analysis}

The statistical analysis of all data was performed by the one-way analysis of variance (one-way ANOVA) using the statistical software, SPSS 13.0. All the data analyzed followed normal distributions and variances. The $p$ values less than 0.05 were considered statistically significant.

\section{Results and discussion}

\subsection{Effects of TCPP on ROS production, apoptosis and antioxidant system}

The mussels $M$. galloprovincialis were exposed to two concentrations of TCCP $\left(10\right.$ and $\left.100 \mathrm{nmol} \mathrm{L}^{-1}\right)$ for 42 days. The reactive oxygen species (ROS) and apoptosis in mussel hemocytes were measured by flow cytometry. Basically, both ROS and apoptosis levels were not significantly different between seawater control and solvent control groups. Therefore, only the mussel samples from solvent control group were used for comparisons in subsequent analysis.

As shown in Fig. 1, ROS productions were highly significantly $(p<0.01)$ elevated in both TCPP-treated mussel samples. In addition, the ROS level in the high dose $\left(100 \mathrm{nmol} \mathrm{L}^{-1}\right)$ of TCPP treatment was significantly higher $(p<0.01)$ than that in the low dose $\left(10 \mathrm{nmol} \mathrm{L}^{-1}\right)$ of TCPP treatment. Obviously, both TCPP exposures enhanced ROS production in mussel hemocytes. As it is known, excessive ROS production may cause cytochrome-c release from mitochondria and induce oxidative and immune stresses, which may lead to cell apoptosis (Zorov et al., 2006). From Fig. 2 , the significantly $(p<0.01)$ increased apoptosis ratio was observed in the high concentration $\left(100 \mathrm{nmol} \mathrm{L}^{-1}\right)$ of TCPP-exposed group. However, the apoptosis ratio in the low concentration $\left(10 \mathrm{nmol} \mathrm{L}^{-1}\right)$ of TCPP-exposed group was not significantly altered. After TCPP exposures for 42 day, interestingly, hemocytes superoxide dismutase (SOD) activity and malondialdehyde (MDA) levels represented similar alterations to that of apoptosis ratio in mussel samples (Fig. 3). Both SOD and MDA play important roles against to the 
Table 1

The list of primers used for the determination of internal control and quantification of gene expressions by qPCR.

\begin{tabular}{|c|c|c|c|}
\hline Gene name & Accession No. & Forward primer (5'-3') & Reverse primer (5'-3') \\
\hline $18 s$ rRNA & L33452 & AGAAACGGCTACCACATCC & TGCCCTCCAATAGATCCTC \\
\hline CLYZ & JQ863366 & GCACCTCATTGACTAACTCGG & CTGAACCCTGGACATTGGAAC \\
\hline GLYZ & JQ244770 & ATCCTAAAGGCATGGCTCCT & TAGCAATACCGGCAATCACA \\
\hline Caspase 2 & HQ424449 & GATATATGACAAGGGTGGCAATG & GACTTTACAGCATCCAGGACATC \\
\hline Caspase 8 & HQ424450 & CCCAACCAGTAGTAACACCAGAC & GTATGAACCATGCCCCTATATCA \\
\hline Mytimacin & FR873274 & CTCCTGCAAATTCCCACATC & ATCTTTTGTTCCGCCAGAGA \\
\hline BD6 & FR873266 & AGCATCATACGCAGGATTGTC & TAGCTCTACACCATCCTCTG \\
\hline MyD88 & JX112712 & GATGTAGGTGTGCTGTTGTCGT & TTTACTGTTTCTTCCAGAGGGATA \\
\hline Galectin & KP125914 & GTGTACCAAATCCAACAGCA & CCAACTTCCGTTCTGACA \\
\hline PGRP & AJQ21541 & AGGCGGTAGTTGTCAGGATG & CCAGTATCATGTTCCACTGCT \\
\hline TLR2 & JX173687 & AACGCCCTCGAATAAGACG & TCGTCCTGCATTACACCAGA \\
\hline LITAF & KF110677 & TTACAGCCACCCAGTATGAGA & TTTACAACCATCCACACAGAATG \\
\hline Jun-like & AJQ21551 & AGCATCGCCAGAGTTAGAAAA & GCAAAAGATTCCTGTTCGTCT \\
\hline
\end{tabular}

Abbreviations: CLYZ, C-type lysozyme; GLYZ, G-type lysozyme; BD6: big defensin 6; MyD88: myeloid differentiation factor 88; PGRP: peptidoglycan recognition receptors; TLR2: toll-like receptor 2; LITAF: lipopolysaccharide-induced tumor necrosis factor-alpha factor; Jun-like: transcription factor effecting in MAPK pathway.

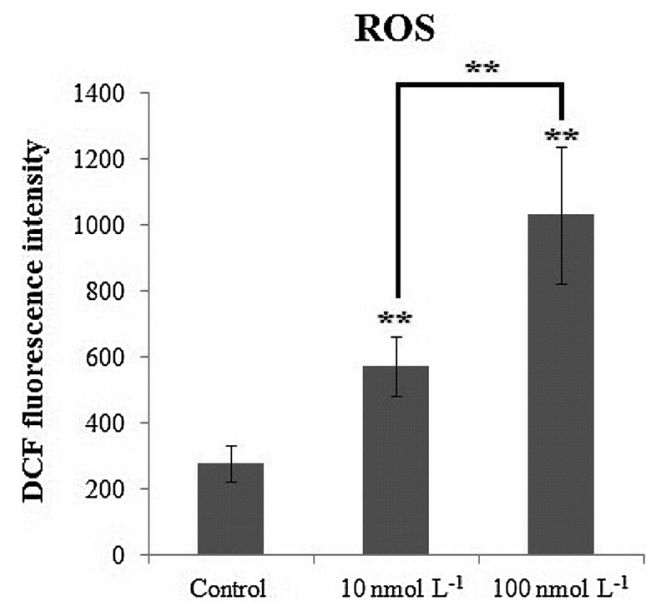

Fig. 1. Reactive oxygen species (ROS) levels in the hemocytes of mussels $M$. galloprovincialis exposed to TCPP for 42 days. DCF: 2',7'-dichlorofluorescin. Significant differences between control and each TCPP treatment and between TCPP treatments were indicated with asterisks $(* *: p<0.01)$.

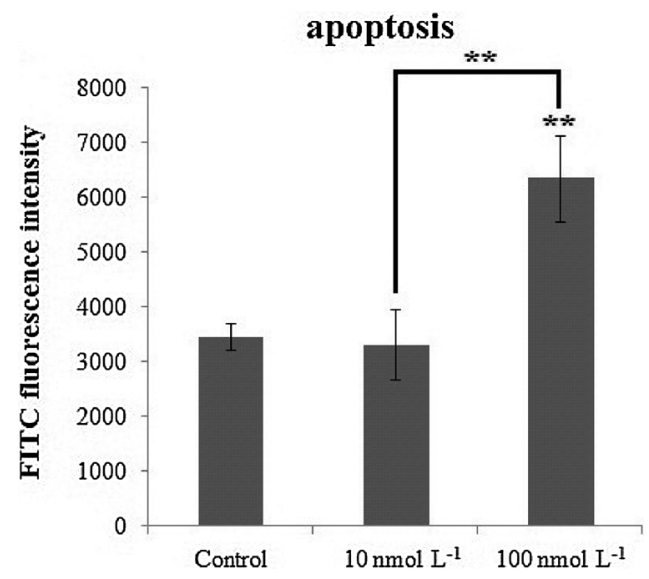

Fig. 2. Apoptosis levels in the hemocytes of mussels M. galloprovincialis exposed to TCPP for 42 days. FITC: fluorescein isothiocyanate. Significant differences between control and each TCPP treatment and between TCPP treatments were indicated with asterisks $(* *: p<0.01)$.

oxidative stress induced by excessive ROS in organisms (Regoli et al., 2011). Therefore the elevated apoptosis ratio, SOD activity and MDA content confirmed that the high dose $\left(100 \mathrm{nmol} \mathrm{L}^{-1}\right)$ of TCPP induced significant oxidative stress in mussel hemocytes. Although the low dose $\left(10 \mathrm{nmol} \mathrm{L}{ }^{-1}\right)$ of TCPP induced significant increase of ROS, no significant oxidative stress was observed in the mussel samples from the low dose of TCPP treatment. It seemed that the increase of ROS produced by the low dose $\left(10 \mathrm{nmol} \mathrm{L}^{-1}\right)$ of TCPP was not up to the threshold to induce oxidative stress in mussel hemocytes.

\subsection{Effects of TCPP on the expressions of immunity related genes}

The hemocytes in mussels are the main immune effector cells involved in multiple intracellular defense mechanisms, including phagocytosis, encapsulation, respiratory burst induction (e.g., generation of superoxide anions) and release of humoral factors (lysosomal enzymes, agglutinins or lectins, cytokine-like molecules, bioactive peptides and antimicrobial peptides) (Canesi et al., 2002; Venier et al., 2011; Gerdol and Venier, 2015). In this work, twelve representative immunity related genes were selected for gene expression quantification to elucidate the effects of TCPP on immunity in mussel M. galloprovincialis. The genes include two lysozymes (G-type and C-type lysozymes), two caspases (caspase 8 and caspase 2), two antimicrobial peptides (mytimacin and big defensin 6), myeloid differentiation factor 88 , toll-like receptor, transcription factor effecting in MAPK pathway (Jun-like), lipopolysaccharide-induced TNF factor 2, galectin and peptidoglycan recognition protein.

Lysozymes are enzymes that cleave $\beta-1,4$ glycosidic bond of peptidoglycan in bacterial cell wall and play important roles in innate immunity against bacterial pathogens (Wang et al., 2013; Wang et al., 2012). As shown in Fig. 4, the expression levels of G-type and C-type lysozymes ( $G L Y Z$ and $C L Y Z$ ) in mussel hemocytes were down-regulated in both TCPP-exposed groups, without or with statistical significances. The down-regulated gene expression levels of GLYZ and CLYZ suggested that both TCPP exposures inhibited the innate immunity in mussel M. galloprovincialis.

Caspases constitute the core of the apoptotic machinery and are classified as initiators or effectors of apoptosis that is an essential biological process in the maintenance and development of homeostasis in immune system. Among the caspase family, caspase 8 is an initiator caspase playing critical roles in diverse apoptotic pathways (Romero et al., 2011). It was interestingly found that the expression level of caspase 8 in the low dose $\left(10 \mathrm{nmol} \mathrm{L} \mathrm{L}^{-1}\right)$ of TCPP treatment was significantly down-regulated. However, this gene expression was significantly up-regulated in the high dose $\left(100 \mathrm{nmol} \mathrm{L}^{-1}\right)$ of TCPP treatment. It seemed that there was a phenomenon of low dose inhibition and high dose stimulation related to caspase 8 expressions induced by TCPP exposure in mussel hemocytes. This phenomenon of low dose inhibition and high dose stimulation (or low dose stimulation and high dose inhibition) has been defined as hormesis, which can be frequently found in toxicology studies on the organic toxic chemicals (Vom Saal et al., 1997; Wetherill et al., 2002). Apparently, the 

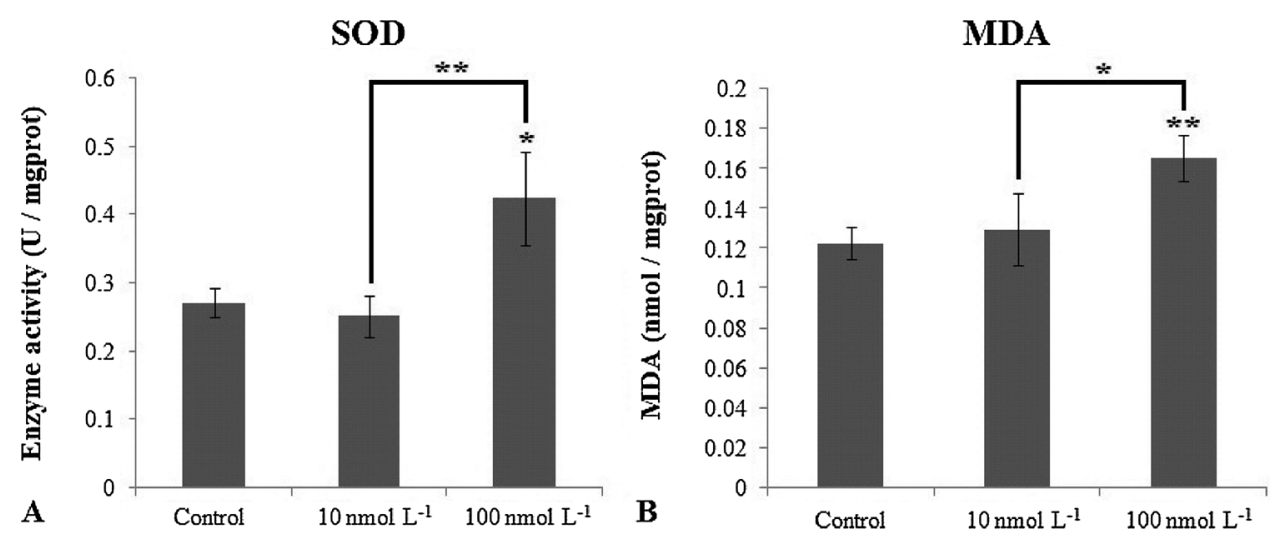

Fig. 3. Superoxide dismutase (SOD) activity and malondialdehyde (MDA) levels in the hemocytes of mussels M. galloprovincialis exposed to TCPP for 42 days. Significant differences between control and each TCPP treatment and between TCPP treatments were indicated with asterisks $\left(*: p<0.05,{ }^{* *}: p<0.01\right)$.

apoptosis ratio in both TCPP treatments revealed the similar profiles compared to that of caspase 8 expression profile (Fig. 2). As an apoptotic initiator, the mRNA levels of caspase 8 can be increased in mussels M. galloprovincialis under stress conditions, such as heat, cold and toxic chemicals which can induce obvious apoptosis (Chiang et al., 2001). Clearly, the gene expression levels of caspase 8 confirmed that TCPP exposures induced hormesis and the high dose of TCPP exposure cause significant apoptosis in mussel hemocytes. Caspase 2 is another initiator caspase that may induce cytochrome-c release and formation of an active complex of cytochrome-c with other apoptotic proteases (Wang et al., 2008). However, the expression level of caspase 2 presented a contrary profile to that of caspase 8 in high dose of TCPP-exposed mussel hemocytes. It might suggest that the gene expression of caspase 2 was down-regulated to compensate for the up-regulation of caspase 8 to maintain the homeostasis of caspases in immune system in mussel hemocytes from the high dose of TCPP treatment.

Big defensin (BD) and mytimacin are two antimicrobial peptides that are humoral components of the innate immunity, playing a fundamental role in the innate immunity in invertebrates lacking adaptive immunity, to prevent the invasion of pathogens (Gerdol et al., 2012). The significant $(p<0.01)$ down-regulation of BD6 suggested that the high dose of TCPP exposure inhibited the innate immunity in mussel $M$. galloprovincialis, as similarly shown by the expression profile of CLYZ. In TCPP-exposed mussel hemocytes, the expression profiles of mytimacin revealed a phenomenon of low dose inhibition and high dose stimulation consistent with that of caspase 8, which confirmed the hormesis effect of TCPP to mussel $M$. galloprovincialis. In addition, the contrary gene expression profiles of mytimacin also showed a compensation mechanism to maintain the homeostasis of BD6 in immune system in mussel hemocytes treated with TCPP. The transcription factor effecting
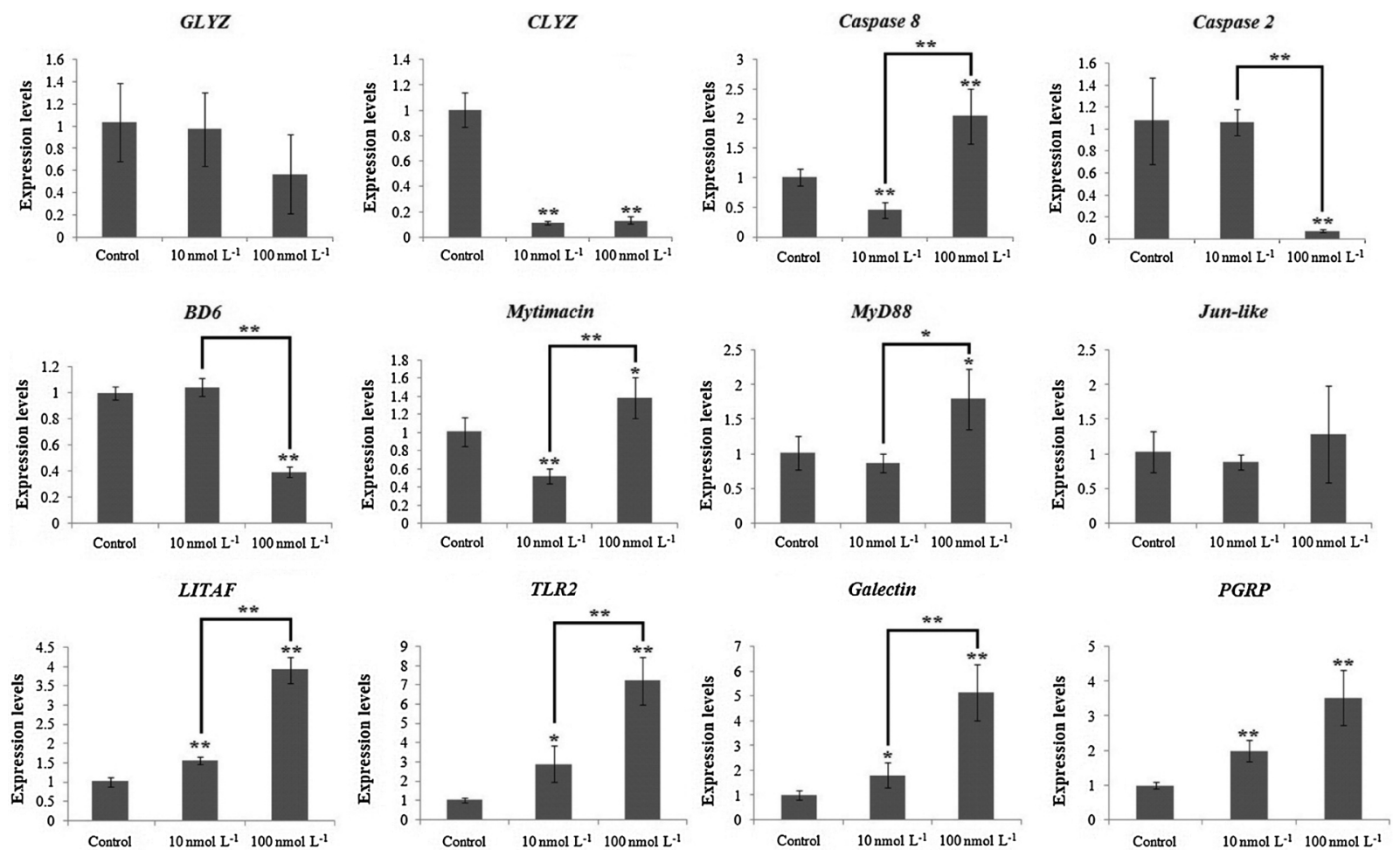

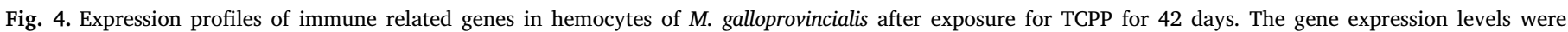

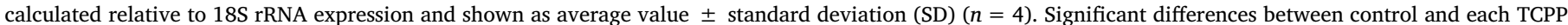

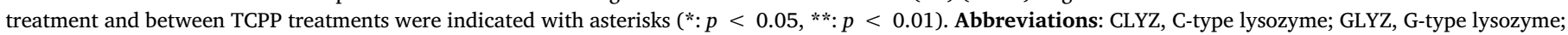

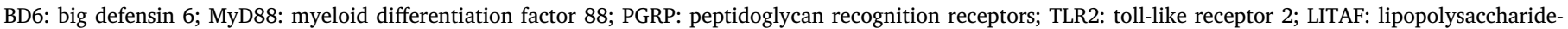
induced tumor necrosis factor-alpha factor; Jun-like: transcription factor effecting in MAPK pathway. 
in MAPK pathway (Jun-like) is responsive to bacterial infections, which has been described in oyster Crassostrea hongkongensis (Gerdol and Venier, 2015). The Jun-like protein is also involved in immune and stress responses. In this study, the Jun-like protein was not significantly altered to TCPP exposures in mussel hemocytes.

Toll-like receptors (TLRs) belong to an ancient family of pattern recognition receptors (PPRs) which play a critical role in initiating and activating the innate immune system, while myeloid differentiation factor 88 (MyD88) is the universal and essential adapter molecule that participate in the signal transduction of TLR signalling pathways under bacterial stimulation (Toubiana et al., 2013). The gene expression levels of TLR and MyD88 were significantly up-regulated in M. galloprovincialis challenged with Vibrio anguillarum, Vibrio splendidus and Micrococcus luteus (Toubiana et al., 2013), which was also observed in the marine bivalve Cyclina sinensis challenged by $V$. anguillarum and $M$. luteus (Ren et al., 2016). Galectins belong to a class of soluble animal lectins and have been indicated as PRRs for bacteria in bivalves specifically bind b-galactoside sugars (Sato et al., 2009). Peptidoglycan recognition receptors (PGRPs) are also important PRRs and able to recognize bacteria by specifically binding peptidoglycan, the major component of bacterial cell walls (Gerdol and Venier, 2015). Lipopolysaccharide-induced tumor necrosis factor-alpha factor (LITAF) is a transcription factor responsible for lipopolysaccharide-induced transcription of tumor necrosis factor-alpha. LITAF is basically involved in immune response against viruses and gram-negative bacteria (Venier et al., 2011). In both TCPP-exposed mussel hemocyte samples, the gene expression levels of TLR, galectin, PGRP and LITAF were significantly $(p<0.01)$ increased in a dose-dependent manner. However, MyD88 was only significantly $(p<0.01)$ overexpressed in the high dose $\left(100 \mathrm{nmol} \mathrm{L}^{-1}\right)$ of TCPP treatment. These findings demonstrated that TCPP induced dose-dependent immune stress in mussels.

\section{Conclusions}

Organophosphate flame retardants (OPFRs) are emerging marine environmental contaminants. Among the OPFRs, the tris (1-chloro-2propyl) phosphate (TCPP) is one of the most frequently detected halogenated OPFRs. In this work, the biological effects of TCCP on the immunity in mussel Mytilus galloprovincialis were characterized by testing the reactive oxygen species, apoptosis, antioxidant system and immunity-related gene expressions. Basically, both TCPP exposures (10 and $100 \mathrm{nmol} \mathrm{L}^{-1}$ ) significantly $(p<0.01)$ enhanced reactive oxygen species production and the high dose of TCPP induced more apoptosis and oxidative stress in mussel hemocytes. An obvious hormesis effect (low dose inhibition and high dose stimulation) was induced by these two TCPP treatments in mussel hemocytes, as indicated by the gene expression profiles of caspase 8 and mytimacin. The down-regulated gene expression levels of lysozymes suggested that both TCPP exposures inhibited the innate immunity in mussel M. galloprovincialis. The significantly $(p<0.01)$ increased gene expression levels of $T L R$, galectin, PGRP and LITAF demonstrated that TCPP induced dose-dependent immune stress in mussels. Overall, this work suggested that TCPP could influence the immune system in marine mussel M. galloprovincialis.

\section{Acknowledgments}

This research was supported by National Key Basic Research Program of China (2015CB453303), the National Natural Science Foundation of China (21677173) and the Youth Innovation Promotion Association CAS.

\section{References}

Wang, R., Tang, J., Xie, Z., Mi, W., Chen, Y., Wolschke, H., et al., 2015. Occurrence and spatial distribution of organophosphate ester flame retardants and plasticizers in 40 rivers draining into the Bohai sea, north China. Environ. Pollut. 198, 172-178.

Zhong, M., Wu, H., Mi, W., Li, F., Ji, C., Ebinghaus, R., et al., 2018. Occurrences and distribution characteristics of organophosphate ester flame retardants and plasticizers in the sediments of the Bohai and Yellow seas. China, Sci. Total Environ. 615, 1305-1311.

Zhong, M., Tang, J., Mi, L., Li, F., Wang, R., Huang, G., et al., 2017. Occurrence and spatial distribution of organophosphorus flame retardants and plasticizers in the Bohai and Yellow seas, China. Mar. Pollut. Bull. 121, 331-338.

Andresen, J.A., Grundmann, A., Bester, K., 2004. Organophosphorus flame retardants and plasticisers in surface waters. Sci. Total Environ. 332, 155-166.

Bacaloni, A., Cucci, F., Guarino, C., Nazzari, M., Samperi, R., Lagana, A., 2008. Occurrence of organophosphorus flame retardant and plasticizers in three volcanic lakes of Central Italy. Environ. Sci. Technol. 42, 1898-1903.

Martinez-Carballo, E., Gonzalez-Barreiro, C., Sitka, A., Scharf, S., Gans, O., 2007. Determination of selected organophosphate esters in the aquatic environment of Austria. Sci. Total Environ. 388, 290-299.

Regnery, J., Puttmann, W., 2010. Occurrence and fate of organophosphorus flame retardants and plasticizers in urban and remote surface waters in Germany. Water Res. 44, 4097-4104.

Reemtsma, T., Quintana, J.B., Rodil, R., Garcia-Lopez, M., Rodriguez, I., 2008. Organophosphorus flame retardants and plasticizers in water and air I. Occurrence and fate. Trac-Trend. Anal. Chem. 27, 727-737.

Ren, X.H., Lee, Y.J., Han, H.J., Kim, I.S., 2008. Effect of tris-(2-chloroethyl)-phosphate (TCEP) at environmental concentration on the levels of cell cycle regulatory protein expression in primary cultured rabbit renal proximal tubule cells. Chemosphere 74, 84-88.

Pillai, H.K., Fang, M.L., Beglov, D., Kozakov, D., Vajda, S., Stapleton, H.M., et al., 2014. Ligand binding and activation of PPAR gamma by firemaster ${ }^{\oplus 50}$ : effects on adipogenesis and osteogenesis in vitro. Environ. Health Perspect. 122, 1225-1232.

Goldberg, E.D., Koide, M., Hodge, V., Flegal, A.R., Martin, J., 1983. U.S. Mussel watch: 1977-1978 results on trace metals and radionuclides. Estuar. Coast. Shelf Sci. 16, 69-93.

Jernelov, A., 1996. The international mussel watch: a global assessment of environmental levels of chemical contaminants. Sci. Total Environ. 188, S37-S44.

Tanguy, M., Gauthier-Clerc, S., Pellerin, J., Danger, J.-M., Siah, A., 2018. The immune response of Mytilus edulis hemocytes exposed to Vibrio splendidus LGP32 strain: a transcriptomic attempt at identifying molecular actors. Fish Shellfish Immunol. 74 (2018), 268-280.

Wang, Q., Wang, C., Mu, C., Wu, H., Zhang, L., Zhao, J., 2013. A novel C-type lysozyme from Mytilus galloprovincialis: insight into innate immunity and molecular evolution of invertebrate C-type lysozymes. Plos One 8, e67469.

Wang, Q., Zhang, L., Zhao, J., You, L., Wu, H., 2012. Two goose-type lysozymes in Mytilus galloprovincialis: possible function diversification and adaptive evolution. Plos One 7, e45148.

Martins, E., Figueras, A., Novoa, B., Santos, R.S., Moreira, R., Bettencourt, R., 2014. Comparative study of immune responses in the deep-sea hydrothermal vent mussel Bathymodiolus azoricus and the shallow-water mussel Mytilus galloprovincialis challenged with Vibrio bacteria. Fish Shellfish Immunol. 40, 485-499.

Gerdol, M., De Moro, G., Manfrin, C., Venier, P., Pallavicini, A., 2012. Big defensins and mytimacins, new AMP families of the Mediterranean mussel Mytilus galloprovincialis. Dev. Comp. Immunol. 36, 390-399.

You, L., 2013. Studies on the Toxicological Effects of Silver Nanoparticles on Mytilus galloprovincialis. Ph.D. Thesis. Yantai Institute of Coastal Zone Research, University of Chinese Academy of Sciences.

Livak, K.J., Schmittgen, T.D., 2001. Analysis of relative gene expression data using real-time quantitative PCR and the 2(-Delta delta C(T)) method. Methods 25, 402-408.

Zorov, D.B., Juhaszova, M., Sollott, S.J., 2006. Mitochondrial ROS-induced ROS release: an update and review. Biochim. Biophys. Acta 1757 (5-6), 509-517.

Regoli, F., Giuliani, M.E., Benedetti, M., Arukwe, A., 2011. Molecular and biochemical biomarkers in environmental monitoring: a comparison of biotransformation and antioxidant defense systems in multiple tissues. Aquat. Toxicol. 105, 56-66.

Canesi, L., Gavioli, M., Pruzzo, C., Gallo, G., 2002. Bacteria-hemocyte interactions and phagocytosis in marine bivalves. Microsc. Res. Tech. 57, 469-476.

Venier, P., Varotto, L., Rosani, U., Millino, C., Celegato, B., Bernante, F., et al., 2011. Insights into the innate immunity of the Mediterranean mussel Mytilus galloprovincialis. BMC Genomics 12, 69.

Gerdol, M., Venier, P., 2015. An updated molecular basis for mussel immunity. Fish Shellfish Immunol. 46, 17-38.

Romero, A., Estevez-Calvar, N., Dios, S., Figueras, A., Novoa, B., 2011. New insights into the apoptotic process in mollusks: characterization of caspase genes in Mytilus galloprovincialis. Plos One 6, e17003.

Vom Saal, F.S., Timms, B.G., Montano, M.M., Palanza, P., Thayer, K.A., Nagel, S.C., et al., 1997 Prostate enlargement in mice due to fetal exposure to low doses of estradiol or diethylstilbestrol and opposite effects at high doses. Proc. Natl. Acad. Sci. U. S. A. 94, 2056-2061.

Wetherill, Y.B., Petre, C.E., Monk, K.R., Puga, A., Knudsen, K.E., 2002. The xenoestrogen bisphenol A induces inappropriate androgen receptor activation and mitogenesis in prostatic adenocarcinoma cells. Mol. Cancer Ther. 1, 515-524.

Chiang, L.W., Grenier, J.M., Ettwiller, L., Jenkins, L.P., Ficenec, D., Martin, J., et al., 2001. An orchestrated gene expression component of neuronal programmed cell death revealed by cDNA array analysis. Proc. Natl. Acad. Sci. U. S. A. 98, 2814-2819.

Wang, L., Zhi, B., Wu, W.L., Zhang, X.B., 2008. Requirement for shrimp caspase in apoptosis against virus infection. Dev. Comp. Immunol. 32, 706-715.

Toubiana, M., Gerdol, M., Rosani, U., Pallavicini, A., Venier, P., Roch, P., 2013. Toll-like receptors and MyD88 adaptors in Mytilus: complete cds and gene expression levels. Dev. Comp. Immunol. 40, 158-166.

Ren, Y., Pan, H., Pan, B., Bu, W., 2016. Identification and functional characterization of three TLR signaling pathway genes in cyclina sinensis. Fish Shellfish Immunol. 50, 150-159.

Sato, S., St-Pierre, C., Bhaumik, P., Nieminen, J., 2009. Galectins in innate immunity: dual functions of host soluble beta-galactoside-binding lectins as damage-associated molecular patterns (DAMPs) and as receptors for pathogen-associated molecular patterns (PAMPs). Immunol. Rev. 230, 172-187. 